\title{
A HISTÓRIA DE NICE: UM CASO DE AMOR, IDEALIZAÇÃO E IDENTIFICAÇÃO EM ORGANIZAÇÕES
}

NICE'S STORY: A CASE OF LOVE, IDEALIZATION AND IDENTIFICATION IN ORGANIZATIONS

LA HISTORIA DE NICE: UN CASO DE AMOR, IDEALIZACIÓN E IDENTIFICACIÓN EN ORGANIZACIONES

MARIANE LEMOS LOURENÇO

Doutora

Universidade Federal do Paraná - Brasil

psimari@uol.com.br

VANUSA CRISTINA DARIO

Mestra

Universidade Federal do Paraná - Brasil vanusadario@hotmail.com

JULLY FABÍOLA NUNES ROGGE

Mestra

Universidade Federal do Paraná - Brasil jullyrogge@hotmail.com

Submetido em: 10/04/2017 Aprovado em: 13/09/2017

Doi: alcance.v24n3.p350-362

\section{RESUMO}

O contexto organizacional vem sendo considerado um dos espaços mais importantes na construção identitária, no qual cada dia mais pessoas encontram identificação e referencial. Neste sentido, o objetivo deste artigo é trazer uma reflexão sobre os processos de identificação e idealização de trabalhadores com as suas organizações. Assim, por meio da abordagem de pesquisa qualitativa e da estratégia de pesquisa história de vida, realizou-se uma reflexão sobre organizações, indivíduos e suas trajetórias. A história é a de Nice, trabalhadora, que teve sua história de vida entrelaçada a de uma organização, de tal forma que os destinos desta organização tocaram a sua vida pessoal. Nice, a protagonista desta história, que teve seu nome escolhido em alusão à deusa grega, que simbolizava a vitória e a força, transitou por cenários de identificação e idealização, permeados por um processo de corrupção que perpassou o seu drama. A análise de sua história revelou o quanto as organizações como espaços de lutas identitárias e jogos de poder podem representar um rompimento na história de seus trabalhadores, sendo necessário um recomeço não sem prejuízos a sua identidade, o que convida a uma reflexão crítica sobre estes acontecimentos e seus atores.

Palavras-chave: Processos de identificação. Corrupção. Contexto.

\section{ABSTRACT}

The organizational context has been considered one of the most important spaces in the construction of identity, where every day, more people find identification and a referential framework. The objective of this article is to bring a reflection on the processes of identification and idealization of workers with their organizations. Thus, through an approach involving qualitative research and the strategy of life story research, a reflection is offered on organizations, individuals, and their histories. The story is that of Nice, a hardworking woman whose life story is intertwined with that of an organization, in such a way that the destinies of the organization touched her personal life. Nice, the protagonist of this story, whose name was chosen in an allusion to the Greek goddess Nike (or Nice, 
in Portuguese) symbolizing victory and strength, moves through scenarios of identification and idealization, permeated by a process of corruption that characterizes her drama. The analysis of her story reveals how organizations, as spaces of identity struggles and power games, can represent a break in the story of their workers, a new beginning becoming necessary, without undermining their identities, which invites critical reflection on these events and their actors.

Keywords: Identification processes. Corruption. Context.

\section{RESUMEN}

El contexto organizacional viene siendo considerado uno de los espacios más importantes en la construcción identitaria, en el cual cada día más personas encuentran identificación y referencias. En este sentido, el objetivo de este artículo es traer una reflexión sobre los procesos de identificación e idealización de los trabajadores con sus organizaciones. Así, por medio de un abordaje de investigación cualitativo y de la estrategia de investigación historia de vida, se realizó una reflexión sobre organizaciones, individuos y sus trayectorias. La historia es la de Nice, una trabajadora que tuvo su historia de vida entrelazada a la de una organización, de tal forma que los destinos de esta organización tocaron su vida personal. Nice, la protagonista de esta historia, cuyo nombre fue elegido en alusión a la diosa griega que simbolizaba la victoria y la fuerza, transitó por escenarios de identificación e idealización, permeados por un proceso de corrupción que atravesó su drama. El análisis de su historia reveló cuánto las organizaciones, como espacios de luchas identitarias y juegos de poder, pueden representar una ruptura en la historia de sus trabajadores, haciéndose necesario un recomienzo, no sin perjuicios a su identidad, lo que invita a una reflexión crítica sobre estos acontecimientos y sus actores.

Palabras clave: Procesos de identificación. Corrupción. Contexto.

\section{INTRODUÇÃO}

Casos de corrupção envolvem as organizações e o cenário político no Brasil, e já parecem fazer parte do cotidiano dos brasileiros, pois tomam os noticiários diariamente. Se se entender as organizações como construções sociais, sujeito e objeto da realidade da qual fazem parte, não é difícil aceitar sua participação, colaboração e indiferença nestes escândalos, pois seja pelo poder econômico que possuem, seja pelo conjunto de competências de que dispõem, as organizações representam uma das instituições mais influentes nos rumos da sociedade contemporânea (VERGARA; BRANCO, 2001; MORGAN, 2007).

Este artigo apresenta a história real de uma brasileira, de origem humilde, que almejou fazer parte de uma destas organizações. A história de Nice retrata esta organização como "objeto de identificação e amor, fonte de prazer e de energia" (MOTTA, 1991, p.11). Organização que "surge assim como uma deusa-mãe a ser adorada, algo como uma nova Médeia que devora aqueles que não se rendem à sua vontade absoluta" (MOTTA, 1991, p.11). Como Nice, muitos "se entregam às organizações" para produzirem trabalho, imersos no universo de intenções e promessas de sucesso e reconhecimento que as empresas constroem, "a fim de melhorarem de vida e serem mais felizes" (SCHIRATO, 2000, p.25). Na sociedade que valoriza imagem, sucesso, dinheiro e poder, a carreira profissional e o status que esta confere tornaram-se elementos estruturantes da vida do indivíduo (FREITAS, 1999). A identidade profissional passa a se confundir com a identidade pessoal, e a organização passa a ser o espaço da realização dos sonhos, o lugar onde todos podem ser vencedores (FREITAS, 1999), a grande fornecedora de significações, gratificações e identidade (ENRIQUEZ, 1992; FREITAS, 1999;).

O objetivo deste artigo é propor uma reflexão sobre os processos de idealização e identificação de uma trabalhadora, Nice, com a organização onde trabalhava. Assim, buscou-se por meio de abordagem de pesquisa qualitativa, e utilizando-se da estratégia de pesquisa de história de vida, uma reflexão sobre organizações e indivíduos, e suas histórias complexas, que vão do amor à angústia ou da relação dual entre estes dois sentimentos. A história é a de Nice, trabalhadora, que teve sua história de vida entrelaçada ao de uma organização, de tal forma que os destinos da organização se entrelaçaram à sua vida pessoal. $O$ nome Nice foi escolhido em alusão à deusa grega alada, que simbolizava a vitória e a força. Justifica-se o estudo desta organização por representar um dos maiores escândalos internacionais de corrupção, que ocasionou o fechamento da empresa no Brasil, e a demissão de milhares de trabalhadores, dentre eles, Nice. Sua história foi escolhida para ajudar a ilustrar o drama vivido por estes trabalhadores. Ressalta-se que a questão da corrupção está associada à corrosão 
do caráter democrático, com consequências graves para o estoque de legitimidade do regime e para o interesse dos cidadãos (WARREN, 2012). Acresce-se a isto o fato de que a percepção e a vivência com atos de corrupção ao longo do tempo levam à conformação das pessoas aos mesmos (BONIFÁCIO; RIBEIRO, 2016), o que necessita ser questionado.

Nice, a protagonista desta história, irá transitar por cenários de amor, identificação, idealização e indiferença, permeados por um processo de corrupção que perpassará seu drama e poderá convidar à reflexão crítica sobre estes acontecimentos e seus atores. A seguir são apresentados os fundamentos teóricos que dão base a este estudo.

\section{O PROCESSO DE IDENTIFICAÇÃO COM AS ORGANIZAÇÕES}

Para se compreender a relação de Nice com a sua organização, torna-se necessário entender o que vem a ser o processo de identificação. A identificação é um processo psicológico por meio do qual alguém "assimila um aspecto, uma prioridade, um atributo do outro e se transforma, total ou parcialmente, segundo o modelo dessa pessoa. A personalidade constitui-se e diferencia-se por uma série de identificações" (LAPLANCHE; PONTALIS, 1985, p.295). Os processos de identificação com as organizações têm sido tema de diversos estudos, e alguns autores têm se destacado dentro desta temática, como Machado-da-Silva e Nogueira (2001); Machado (2003); Freitas (2006); Carrieri (2010); Vieira (2012), e também autores internacionais, como Dutton et al. (1994), Dukerich et al. (1998); e, anteriormente, Berger e Luckman (1973; 2012). E mais recentemente: Backes (2013); Castells (2013); Lorentz et al. (2014); Cheney, Christensen e Dailey (2014); Marra et al. (2014); Brown (2014); Minini e Ferraz (2015); Patvardhan, Gioia e Hamilton (2015); Barros et al. (2016); Carrieri et al. (2016); Colares e Saraiva (2016); Marra et al. (2016); Hanell (2017) e Cabana e Ichikawa (2017).

A importância destes estudos está na tentativa de decifrar como a identificação pode ter efeitos positivos ou negativos nos indivíduos, principalmente ao tentar compreender a identificação com o trabalho como o centro de toda a sua vida emocional, tornando-se até algo patológico. Neste sentido, Pagès et al. (1987) e Motta (1991) apontam o quanto a identificação do indivíduo com a organização pode se dar como forma de dominação. Pagès et al. (1987) chamam a atenção para o fenômeno da autonomia controlada que permite a expressão da identidade, mas ao mesmo tempo programa, enquadra, canaliza e assimila a subjetividade do indivíduo de acordo com as regras da organização. Essa situação é, possivelmente, uma crescente tendência nas organizações de hoje, devido à falência das demais comunidades organizadas, nas quais os sujeitos poderiam transferir suas necessidades de pertencimento, como a família, os grupos e até mesmo na religião, não necessitando para isso viverem em função do trabalho, para ali poderem satisfazer seus desejos de ego, de reconhecimento e valorização. Deste modo, segundo Motta (1991), as organizações podem se apresentar como local de realização de projetos e desejos, sendo impossível para muitas pessoas conceberem as suas vidas distantes das organizações.

Aubert (1994) demonstra que a excessiva identificação do indivíduo com a organização pode causar uma enorme frustração e um sentimento de perda da identidade no momento em que a empresa rompe o contrato psicológico estabelecido. É preciso que o indivíduo se identifique com a atividade que ele realiza e não com a organização que lhe dá o emprego. E isto que diferencia uma demissão que destrói a vida do indivíduo daquela que é capaz de transformá-la positivamente. Os estudos empíricos de Dutton et al. (1994) sobre as imagens da organização e a identificação de seus membros mostrou que quando é alta a identificação com a organização, os atributos que definem a organização também definem 0 indivíduo. A identificação organizacional seria um processo no qual as pessoas se entrelaçam psicologicamente com a organização e a partir do qual reconhecem a identidade organizacional. Os atributos percebidos pelo sujeito como centrais, distintivos e duradouros na organização, com os quais se identifica, são exteriorizados contribuindo significativamente para a construção da imagem externa da organização, imagem esta que por sua vez reforça a identificação do indivíduo completando 0 círculo. Uma forte identificação organizacional é traduzida em resultados desejáveis e conduta cidadã, gerando orgulho em pertencer. Por outro lado, uma percepção negativa em relação à empresa pode gerar efeitos negativos no sujeito, como stress e depressão (DUTTON et al., 1994).

Para entender como este processo ocorre, Ashforth e Mael (1996) reforçam que a identidade organizacional é uma construção intersubjetiva sobre as crenças e os valores individuais e dos grupos. Complementarmente, Caldas e Wood Jr. (1997) acrescentam que o processo de identificação ocorre pela identificação do autoconceito do indivíduo com a imagem da organização, de modo que estas áreas passam a se interseccionar até que possam se sobrepor e fundirem-se. Já Dukerich et al. (1998) falam de uma extrema identificação dos indivíduos com a organização, algo prejudicial, quando passa a incluir a negação da realidade

Revista Alcance - Eletrônica - vol. 24 - n. 3 - jul./set. 2017 
vivida dentro das organizações e o repúdio de valores anteriormente considerados importantes. Mas, para os autores, este processo de "extrema identificação" dos indivíduos com suas organizações, não seria bom ou mau, mas simultaneamente bom e mau. Para alguns indivíduos, a "extrema identificação" com a organização pode satisfazer uma necessidade em suas vidas se outras identificações estiverem indisponíveis (por exemplo, indivíduos que estejam experimentando uma mudança de vida, como um divórcio). A organização provê assim um sentido para a vida e para a identidade. No entanto, a "extrema identificação" pode ser disfuncional também, pois algumas pessoas podem identificar-se unicamente com a organização, desconsiderando outros aspectos da vida, e apresentando inabilidades para separar a própria vida da organização (DUKERICH et al., 1998).

Enriquez (2002) corrobora com esta visão ao afirmar que no auge da identificação do indivíduo com a organização o ideal do ego do indivíduo se confunde completamente com o ideal da organização. E seria a organização que impele o indivíduo a idealizá-la e a identificar-se com ela, por meio de seus elementos culturais, a fim de que este the devote seu amor incondicional e faz isto com a criação de um mito coletivo, ou uma ideologia, que impede outras visões de mundo, fazendo com que valores e normas organizacionais sejam incorporados pelos membros da organização a ponto de constituírem traços de sua própria identidade (ENRIQUEZ, 2002, p.19). Esta ótica suscita abordagens distintas, desde a percepção dos indivíduos, que passa pelo campo psíquico, nas três dimensões do que é percebido como distintivo, central e duradouro, até a construção externa da imagem da organização, fundamentada em território bem mais abrangente entre 0 ambiente interno e 0 externo, e os elementos da cultura organizacional.

Em Freitas (2002, p.52) "o imaginário produzido pelas grandes organizações modernas busca responder à problemática atual da fragilidade no processo de identificação dos indivíduos". Esta afirmação conduz à reflexão das possibilidades de identificação de indivíduos com as organizações. Sabe-se que a identificação se estabelece por meio dos aspectos culturais percebidos pelos seus membros, sendo estes grandes fontes de identificação. Enriquez (2002) acredita que se vive sob a fragilidade dos processos de identificação, por conta das banalizações e da dessacralização das instituições clássicas no mundo moderno, o que coloca as organizações modernas em condições únicas para gerar um imaginário capaz de ser idealizado. Contudo, para o autor, a idealização pode tornar-se uma doença à medida que a organização pede aos indivíduos não só para idealizá-la e identificar-se com ela, mas também lhe dedicar amor e devoção incondicionais, em que tem seu auge quando 0 ideal do ego se confunde completamente com o ideal da organização.

Esta visão, de acordo com Tonelli e Caldas (2002), está amparada na psicanálise sob a qual o processo de identificação está intimamente ligado ao próprio desenvolvimento humano. É por meio do processo de identificação que o sujeito percebe a si e aos outros e estabelece vínculos. Machado (2003) cita a importância da empresa como instituição secundária de socialização e dos papéis, que compõem parte da estrutura de identificação dos indivíduos. Neste sentido, Hatch e Shultz (2004) afirmam que a identidade organizacional está em constante transformação à medida que é compartilhada pelos seus membros e se modifica pela ação e pela significação destes. Os tipos de relacionamentos, de relações de trabalho e de poder mantidos na organização, também são apresentados como fator importante no processo de identificação organizacional. Os estudos empíricos de Machado (2005) mostraram que a conjugação dos sonhos individuais com as boas perspectivas da organização pode interferir na identificação organizacional. Entretanto, a idealização do sonho implicou a dificuldade, por parte dos entrevistados daquela pesquisa, em estabelecer os limites do "eu" e os da organização (MACHADO, 2005).

Freitas (2006) aponta que a identidade profissional se tornou a identidade pessoal, já que atualmente as sociedades vêm sendo atravessadas por crises culturais e de identidade, e as organizações têm buscado suprir essas carências. No entanto, uma identidade individual autônoma pode ser ameaçada com uma possível identificação dos indivíduos com Organizações Sedutoras, que podem projetar uma imagem grandiosa e onipotente. Dentro destas organizações, o devotado corre o risco de reduzir ou mesmo eliminar sua capacidade de julgamento, de distorcer demais sua percepção, de fechar-se numa relação circular que anula os demais, de inibir qualquer crítica. Para a autora o destino dos seduzidos seria o abandono, visto que o sedutor não permanece em um mesmo lugar, ou melhor, seu lugar é o da mudança, da surpresa, do novo. Da mesma forma que o personagem de Don Juan figura com grande poder de sedução, que deixa suas vítimas por onde passa (mulheres seduzidas, apaixonadas e abandonadas); nas organizações sedutoras, o papel das "mulheres seduzidas" é desempenhado pelos indivíduos que lhes dedicam suas vidas, movidos pela paixão, porém sem nenhuma promessa de fidelidade, pelo contrário, a cada movimento, mudança ou novidade do sedutor, os seduzidos ficam para trás, assim como na lista de conquistas esquecidas de Don Juan.

Assim, segundo Fernandes, Marques e Carrieri (2009), os estudos sobre identidade e identificação 
permitem compreender o significado que os trabalhadores conferem às organizações, pelo modo que assimilam os valores e as qualidades organizacionais, de como se definem "como membros de uma mesma organização e da relevância das organizações na sua autodefinição e autoestima" (FERNANDES et al., 2009, p.688). Estes autores ainda afirmam que 0 interesse dos teóricos organizacionais sobre o tema identificação organizacional é recente ao assumirem se tratar de um processo pelo qual as pessoas integram a sua autodefinição à identidade organizacional, tanto pelo reconhecimento de afinidade entre os valores da organização e os do sujeito, quanto pela transformação nos valores e nas crenças pessoais, para se tornarem mais semelhantes aos da organização. A identidade pessoal e a identidade coletiva (ou, como aqui, a identidade organizacional) resultam das relações intersociais, numa relação de comparação, identificação e distinção em relação ao outro, chamada alteridade, a partir da qual os seres humanos se percebem e definem como indivíduos à medida que se comparam entre si. Esta alteridade ocorre sobre o pano de fundo da cultura organizacional e seus elementos, principalmente valores e crenças compartilhados pelos membros organizacionais. As citações a seguir reforçam esta perspectiva:

\begin{abstract}
Dessa forma, a imagem pauta-se no modo como o indivíduo percebe a identidade da organização por meio do que define como central, distintivo e duradouro. (ALBERT; WHETTEN, 2004).

A outra imagem está relacionada ao modo como o indivíduo acredita que os membros externos percebem a organização em que ele está inserido, ou seja, a imagem construída externamente à organização. (LOURENÇO et al., 2014, p.448)
\end{abstract}

Na perspectiva da construção social da realidade, é por meio do processo de identificação e apreensão subjetiva dos significados do mundo exterior que o indivíduo é capaz de se autoidentificar. 0 ambiente organizacional vem sendo considerado um dos espaços mais importantes de socialização secundária (BERGER; LUCKMANN, 2012), em que cada dia mais pessoas encontram identificação e referencial. Deste modo, as organizações podem exercer um controle muito intenso para aqueles que nelas trabalham; estes trabalhadores poderiam ser comparados aos habitantes da caverna de Platão, que acreditavam ser a realidade que viviam a única verdade possível, sem nenhuma consciência crítica, nada vendo além das sombras. Platão ajuda assim a ilustrar a relação, por vezes, problemática das pessoas com as organizações, na qual visualizar somente as sombras pode conduzi-los "a conviver com contradições, rompimentos, incertezas e ameaças que desestabilizam a sustentação da sua identidade" (BACKES, 2013, p.27).

0 atual contexto organizacional pode então fragilizar os processos identificatórios, fragmentando as relações sociais, criando laços tênues e frágeis entre os indivíduos e a organização (LORENZ, et al., 2014, p.226), transformando por vezes os trabalhadores em "fantoches de um teatro de enredo criado pelos gestores e pelo capital" (COLARES; SARAIVA, 2016, p.569). As organizações seriam, assim, o palco de lutas identitárias, arrogando para si o poder de definir a identidade e sinalizar o diferente (CABANA; ICHIKAWA, 2017). A seguir serão apresentados os aspectos metodológicos que guiam este trabalho, na intenção de entender estas questões.

\title{
3 PROCEDIMENTOS METODOLÓGICOS
}

A pesquisa aqui apresentada emprega a abordagem qualitativa, visto que essa representa um meio pelo qual se pode entender o significado que se atribui a um problema social ou humano, isso aliado ao caráter multidisciplinar dos estudos organizacionais, nos quais diferentes modos de acesso e contextualização da realidade podem coexistir. Assim, busca-se através da pesquisa qualitativa uma descrição densa dos fatos, buscando a compreensão das experiências humanas, dentro de determinado contexto (CRESWELL, 2010; GODOI; BALSINI, 2010; STAKE,1995).

Contudo, não há uma janela de entrada à vida particular de cada pessoa (DENZIN; LINCOLN, 2006). Isso faz com que a pesquisa qualitativa exija do pesquisador um esforço interpretativo, que segundo Creswell (1998), se traduz como 0 ato de interpretar os fenômenos a partir dos significados que as pessoas dão a ele. Ainda nesse sentido, a pesquisa qualitativa baseia-se na capacidade de observação dos cientistas e na confiança na percepção do pesquisador, na sua sensibilidade e memória (RICHARDSON, 1989).

Os conceitos para a pesquisa aqui apresentada partem de pressupostos de que a construção social acontece por via das interações intersubjetivas dos seres humanos. 0 mundo da vida cotidiana, comum a todos, se torna único e particularmente observado a partir da história pessoal resultante de todas as experiências do indivíduo. A partir disso, buscam-se formas de explicar o mundo, o comportamento dos indivíduos e,

Revista Alcance - Eletrônica - vol. 24 - n. 3 - jul./set. 2017 
principalmente, os fenômenos dentro das organizações. Para isso, o uso da estratégia de história de vida é utilizado para esta pesquisa. A história de vida é uma das abordagens em pesquisa qualitativa que compreende o estudo aprofundado da vida de um indivíduo, ou de um grupo de indivíduos, e ressalta o momento histórico vivido por estes (SPINDOLA; SANTOS, 2003). Ainda, a história de vida propõe uma escuta comprometida, engajada e participativa. Na relação de cumplicidade entre pesquisadores e sujeitos pesquisados, encontra-se a possibilidade daquele que narra sua história experimentar uma ressignificação de seu percurso e dar continuação à construção de um sentido frente a este relato endereçado (NOGUEIRA, 2004; SILVA et al., 2007).

Segundo Silva et al. (2007), o método de História de Vida é um método científico com toda força, validade e credibilidade de qualquer outro método, sobretudo porque revela que por mais individual que seja uma história, ela é sempre, ainda, coletiva, mostrando também quão genérica é a trajetória do ser humano. Na área da administração diversos trabalhos têm sido elaborados via história de vida, como as pesquisas de: Waiandt e Junquilho (2012); Oliveira e Closs (2013); Closs e Rocha-de-Oliveira (2015); Ferreira e Godoy (2015); Colares e Saraiva (2016); Oliveira et al. (2017), entre outros.

Nesta pesquisa, que empregou a metodologia de História de Vida, a protagonista da história é Nice, trabalhadora que teve sua história de vida entrelaçada à de uma organização envolvida em um caso de corrupção, de tal forma que os destinos da organização se entrelaçaram à sua vida pessoal. $O$ contato com Nice ocorreu no encontro de um dos pesquisadores deste artigo com trabalhadores que laboraram na organização MDA. Em um destes encontros, Nice relatou um pouco de sua trajetória naquela organização e foi convidada por um dos pesquisadores a compartilhar toda a sua história em razão da mesma ser representativa da trajetória de outros trabalhadores daquela organização. Neste contato foi explicado que seria garantido total sigilo em relação ao seu nome e o da empresa na qual havia trabalhado. Assim, a primeira entrevista com Nice foi agendada previamente, sendo realizada em local de sua escolha. Nesta primeira entrevista, Nice discorreu livremente sobre sua trajetória de vida. Foi solicitado a Nice uma segunda entrevista, na qual relatou detalhes relacionados à sua entrada na organização, a questões pertinentes ao trabalho lá realizado e aos seus projetos futuros depois de sua demissão daquela empresa. As entrevistas totalizaram quatro horas e, após transcritas, foram analisadas de acordo com a análise de conteúdo (BARDIN, 2012).

Dados secundários de jornais e revistas também foram analisados para contextualizar o cenário vivido por Nice. $\mathrm{O}$ nome Nice foi escolhido em alusão à deusa grega alada, que simbolizava a vitória e a força. A organização será nomeada de MDA em alusão a Médeia, figura da Mitologia que Motta (1991) compara às organizações, que semelhantes a uma deusa-mãe, devoram aqueles que não se entregam aos seus desejos absolutos. O nome da personagem assim como o nome da organização e seu ramo de atividades foram trocados por questões de sigilo, para preservar suas histórias.

Conforme já mencionado, as entrevistas realizadas com Nice foram transcritas, e os dados foram analisados com base na técnica de análise de conteúdo, conforme proposto por Bardin (2012). Para Richardson (1989), a análise de conteúdo vai além da apreensão da frequência das características presentes na mensagem, sendo preciso compreender o homem, sua história, seu pensamento, sua arte e suas instituições. A análise de conteúdo é tema central para as ciências humanas e tem se transformado em um instrumento importante para 0 estudo das interações entre os indivíduos (RICHARDSON, 1989). Após a análise de conteúdo (BARDIN, 2012), emergiram as seguintes categorias temáticas: identificação pessoal, identificação profissional e processos de identificação e identificação com o trabalho. Além da análise dos relatos de Nice, utilizou-se de ampla pesquisa teórica sobre os conceitos de identidade e processo de identificação, para que fosse possível identificar por meio das falas da entrevistada sua trajetória de vida.

\section{DISCUSSÃO E RESULTADOS}

Nice trabalhava em uma filial brasileira de uma multinacional do ramo automobilístico desde 2009. A filial brasileira era reconhecida como uma das maiores em sua área no Brasil, contando com filiais presentes em muitas cidades brasileiras. Suas atividades no Brasil iniciaram nos anos 1990, com a compra de uma outra empresa do setor cuja falência havia sido decretada naquele mesmo ano. Em 2015, ao completar quase duas décadas de atividades no Brasil, já possuía ativos totais de mais de 100 bilhões de reais, além de contar com um quadro de mais de 20 mil funcionários no país. Foi neste mesmo ano que a matriz da multinacional teve seu nome envolvido em escândalos de corrupção, com a denúncia de que trabalhava com dinheiro não declarado em suas operações. A partir de tais denúncias, a diretoria da multinacional decidiu fechar suas filiais no Brasil, para 
contrabalançar o impacto nos resultados do aumento das exigências dos órgãos reguladores de diversos países. Afetada por problemas com raízes profundas, a multinacional viu-se obrigada a enxugar a sua estrutura em um esforço de sobrevivência. $O$ resultado desta situação foram milhares de demissões, estimadas em 50 mil funcionários, considerando Brasil e outros países.

Para simbolizar estas pessoas que viveram esta situação de perda de seu trabalho, conta-se neste texto a história de Nice, funcionária dedicada a esta organização, que trabalhou intensamente, e até pode-se dizer, com um amor incondicional e alto grau de identificação e idealização, visto que Nice almejava trabalhar nesta empresa desde que iniciou sua carreira profissional. Esta é uma história real, o nome da personagem principal, como já mencionado, vem da mitologia grega, Nice, deusa grega que personificava vitória, força e velocidade, representada por uma mulher alada. A brasileira Nice formou-se com toda a dedicação e esforço de uma garota pobre no Brasil. Estudou à noite, enquanto trabalhava durante todo o dia. Ela sonhava em se formar, para melhorar a sua condição de vida:

\begin{abstract}
Todos os dias era um novo desafio, ir para o trabalho... correr para a Universidade. (...) ao fim de mais um dia de trabalho o destino não era a minha casa. 0 destino era ir direto para a Faculdade. De novo o ônibus cheio, e mais uma noite de estudos. De novo era preciso lutar contra o sono. Sabe, às vezes parecia difícil prestar atenção no que era falado nas aulas. $E$ no intervalo da aula, descia para tomar um café bem forte, e tentar aproveitar ao máximo de cada aula. E depois de novo correr para casa dormir. E, no outro dia começar tudo de novo. Vou falar que a Universidade para mim eu via como uma grande oportunidade. Uma oportunidade de mudar de vida, de conseguir um bom trabalho. Um trabalho dos sonhos, poder ir trabalhar em uma grande companhia. Já quando comecei o meu curso, eu pensava em ir trabalhar na empresa MDA. Enfim, minha família é de origem bem humilde, minha mãe é uma pessoa muito simples, ela tem até vergonha de ir a lugares mais sofisticados. Minha família é muito humilde e simples, eu precisava me dedicar muito ao meu trabalho e ao meu curso. (Depoimento de Nice)
\end{abstract}

O processo de identificação de Nice com a organização iniciou já durante o período da Universidade, pois a empresa MDA era um lugar de sonhos, de grande idealização. A organização MDA tornou-se um ideal nos sonhos de Nice, poder-se-ia falar em um Ideal de Ego no sentido psicanalítico do termo. Ao trazer a questão dos processos inconscientes no estudo das organizações, é necessário lembrar que o ideal do ego é também "aquilo que queremos ser", diferentemente do superego, que representa "aquilo que devemos ser e fazer" (FREITAS, 1999, p.86). É pela "projeção do ideal do ego que o indivíduo gera a idealização das organizações. Este fenômeno é característico de empresas administradas pelo pressuposto da excelência". Segundo Aubert (2012), ao buscar por padrões de desempenho continuamente em elevação, geram uma imagem de si na mesma intensidade de perfeição. O relato de Nice mostra que ela não mediu esforços em prol deste tão idealizado objetivo:

Do meio para o final da faculdade comecei a perceber que o mercado de TI estava muito aquecido e com boas oportunidades no mercado de trabalho. Comecei então a me dedicar a esta área. Comecei a ler muito e a me preparar. A rotina durante a semana era bem pesada, correr da casa para o trabalho, do trabalho para a Universidade e da Universidade de volta 0 mais rápido possível para casa.

E, voltava para a Universidade já bem tarde. Algumas vezes eu sentia medo de ficar no ponto de ônibus até tão tarde da noite. E, no outro dia a mesma rotina, mas eu tirava força dos meus sonhos para continuar. No final de semana, eu quase não saia, pois tinha muita coisa para fazer e estudar. Passava o final de semana estudando. Eu tinha um sonho de conseguir um bom trabalho. De preferência na empresa MDA. Era preciso continuar estudando e me dedicando muito para fazer o melhor, para fazer parte daquela empresa! (Depoimento de Nice)

A idealização para Enriquez (2002) pode se tornar uma doença à medida que a organização pede aos indivíduos não só para idealizá-la e identificar-se com ela, mas também lhe dedicar amor e devoção incondicionais, as quais têm seu auge quando o ideal do ego se confunde completamente pelo ideal da organização. Na história de Nice é marcante o momento de realização deste ideal: 
Quando me formei a vontade aumentou de fazer parte de uma grande empresa, para mim aquela empresa MDA deveria ser o melhor lugar para se trabalhar. Eu admirava muito aquela empresa. Queria fazer parte dela. Eu queria muito trabalhar naquele lugar. Era a empresa dos meus sonhos. Isso passou a ser o meu objetivo de vida, uma grande meta. E comecei a prestar atenção a todos os processos seletivos da empresa, me sentia preparada. Queria estar lá. Bom, por este tempo me casei. Já estamos há oito anos casados, mas nós não temos filhos. Eu precisava primeiro de um bom trabalho, e trabalhar na MDA era a minha meta. Estava sempre atenta aos processos seletivos na empresa. Um certo dia apareceu a oportunidade, e me inscrevi no Processo Seletivo do MDA. Foi um processo bem rigoroso, e foi para a área que eu estava me preparando, a área de T.I. Para a minha felicidade, fui aprovada no Processo Seletivo, para a área que eu almejava para a área de T.I. na MDA. Foi a realização de um grande objetivo de vida! (Depoimento de Nice)

A organização MDA era para Nice objeto de identificação e amor, segundo Motta (1991), deste modo, o trabalhador passa a internalizar como seus a filosofia, a política, as regras, as normas e os símbolos da organização. Portanto, para Nice ter finalmente realizado seu sonho, estar na empresa MDA intensificou a sua identificação com a organização e trouxe um sentimento intenso de dedicação, não era preciso vigiá-la ou acorrentá-la. No brilhante e clássico texto, o Discurso da Servidão Voluntária, Etienne La Boétie (2006) mostra como ocorre este processo de servidão:

\begin{abstract}
Esse que tanto vos humilha tem só dois olhos e duas mãos, tem um só corpo e nada possui que o mais ínfimo entre os ínfimos habitantes das vossas cidades não possua também; uma só coisa ele tem mais do que vós e é o poder de vos destruir, poder que vós lhe concedestes. Onde iria ele buscar os olhos com que vos espia se vós não lhes désseis? Onde teria ele mãos para vos bater se não tivesse as vossas? Os pés com que ele esmaga as vossas cidades de quem são senão vossos? Que poder tem ele sobre vós que de vós não venha? Como ousaria ele perseguir-vos sem a vossa própria conivência? Que poderia ele fazer se vós não fôsseis encobridores daquele que vos rouba, cúmplices do assassino que vos mata e traidores de vós mesmos. (LA BOÉTIE, 2006, p.13-14).
\end{abstract}

O depoimento a seguir de Nice traz aspectos desta servidão voluntária às organizações, "uma só coisa ele tem mais do que vós e é o poder de vos destruir", todo "o poder que vós lhe concedestes". Nice fazia o melhor, servia voluntariamente:

Fazer parte da empresa MDA, só fazia me dedicar ao máximo todos os dias, todos os momentos. Em um certo tempo, fui promovida a líder de equipe. Então nos momentos de fechamento de Projetos eu trabalhava de 10 a 12 horas por dia. Sempre acordando bem cedo, trabalhando até tarde. Trabalhava muito, intensamente, precisava e sempre me dediquei para fazer o melhor. Os planos de ter um bebê nem foram cogitados por mim e por meu marido nos primeiros anos de empresa. A dedicação, empenho, energia, tudo foi dedicado à empresa. (Depoimento de Nice)

De acordo com Pagés et al. (1987), cada sujeito seria tomado por um desejo perpétuo de superar-se e, para alcançar esta meta, aceita-se a escravidão. A ambição de seguir carreira incentiva cada sujeito pelo comprometimento de vencer e não somente pelo compromisso de trabalhar. Para 0 autor, sendo acionado 0 dispositivo, não seria preciso designar grande encargo de tarefas e tampouco vigiar o tempo de trabalho de cada pessoa na organização. Este foi o percurso de Nice na empresa MDA. Todo o ambiente familiar de Nice estava cercado pela organização, seu marido também tinha a vida dedicada à MDA:

Ah, meu marido também era funcionário da MDA... também muito dedicado. Ele trabalhava em outra área. Para ele também o trabalho era sempre bem intenso. Nos momentos de pico ele trabalhava até mais de 12 horas por dia. Eu ia dormir e muitas vezes adormecia sem ele ter voltado para casa ainda, pois estava no trabalho. Depois meio adormecida eu o via na cama, já dormindo do meu lado de madrugada. E, ele já saía cedo para o trabalho, muito cedo 
também. (Depoimento de Nice).

O compromisso de Nice com a organização sempre foi sério e intenso, Freitas (2007) compara a história de Don Juan e Casa Nova com as organizações contemporâneas. Um processo de sedução intenso, bons salários, benefícios, mas não há um compromisso verdadeiro das organizações com seus "colaboradores", não há uma aliança. A qualquer momento podem ser deixados, trocados por outros. Mas Nice apenas amava a sua organização e se dedicava, não percebia este processo, em nenhum momento de seus depoimentos disse qualquer coisa de negativo, em relação à "idealizada" organização. Toda a dedicação de Nice à organização fez com que ela abrisse mão de muitos outros objetivos, muitas questões foram relegadas a um plano secundário. Entre estes planos, algo bem especial começou a figurar em seus pensamentos:

Nos primeiros anos de empresa o sonho de ter um bebê, nem sequer foi cogitado. Mas, nos últimos dois anos essa vontade começou a aparecer. Começou a ser o momento certo para termos um filho.

Nossa vida era bem corrida, muito trabalho, muita dedicação, quanto empenho. Nos últimos anos a nossa renda familiar estava muito boa. Crescemos no nosso trabalho. Para mim era uma extrema felicidade estar trabalhando na empresa MDA, a empresa dos meus sonhos, do meu projeto de vida. Tive um ganho salarial ainda melhor. E, pensamos que já aos 32 anos poderia ser o momento de termos o nosso bebê. Conversei com a minha médica, e fiz todos os exames que ela pediu para ver se eu poderia ter um bebê. Meu marido também realizou exames neste sentido, para ver se estava tudo bem com ele, para termos nosso filho. (Depoimento de Nice)

Depois de um longo caminho, depois do tempo difícil na Universidade, onde conciliou bravamente, em meio a tanto cansaço e esforço, trabalho e estudo... Depois de todo o tempo dedicado à empresa MDA um sonho diferente começou a brotar no seu coração. Neste momento Nice tinha por certo que estaria tudo bem. Mas, depois de tudo, o que se mostrou foi um pouco diferente:

Era o momento, comecei a tomar ácido fólico, começamos a nos preparar. Sabe? Mesmo com os problemas na MDA eu sempre me dediquei muito a esta organização, era o meu grande projeto de vida, uma grande empresa, fiz o melhor sempre. Mas em outubro eles me chamaram para conversar e disseram que eu estava demitida. Eu não entendi o porquê, eu me dediquei tanto, fiz o melhor sempre. Meu mundo caiu naquele dia, desmoronou, fiquei sem rumo. Chorei muito, chorei por três dias seguidos sem parar, não sabia o que fazer.

Foi o momento mais triste que passei na vida. Procurei outros trabalhos, mas não estou conseguindo. Aqui o mercado de trabalho está difícil. Meu marido foi demitido em novembro. O sonho do nosso bebê não pode ser mais, não temos mais trabalho, não temos mais condições de termos o nosso bebê. Mas eu imagino ele crescendo e correndo na nossa casa. Mas, não temos como agora.... (Depoimento de Nice)

E quando as promessas não são cumpridas? Parece que de uma forma ou de outra a empresa sempre falhará em suas promessas, pois estas são irreais, na prática o paraíso prometido não se realizará (FREITAS, 1999), o que tem impactos importantes na identidade dos indivíduos que, assim como Nice, devotam suas vidas às organizações. Segundo Backes (2013), as transformações que acontecem nas organizações podem representar para aqueles que nelas trabalham um risco, uma quebra na sua história, e marcar a necessidade de um recomeço, o que pode impactar na identidade do trabalhador. Para Nice, as mudanças ocorridas em MDA representaram um rompimento em sua história e trouxeram riscos à sua própria identidade, pois um contexto instável, desestabilizado por problemas de corrupção pode "fragilizar os processos identificatórios" (LORENZ et al., 2014), que dão base para as identidades almejadas pelos sujeitos (MININI; FERRAZ, 2015, p. 184), compreendendo que a identidade de cada pessoa não é somente formada por suas escolhas individuais, possuindo o contexto, e as instituições grande poder no processo de construção identitária (COLARES; SARAIVA, 2016). 
O episódio de corrupção que envolveu a organização em que Nice trabalhava fez com que a organização fechasse suas portas no Brasil, o que culminou no seu processo de demissão e na exclusão do seu papel de trabalhadora e também de mãe. A história de Nice corrobora com o que foi apontado por Cabana e Ichikawa (2017, p.289), no qual as organizações são palco de "lutas identitárias e do jogo do poder". No caso de Nice, sua identidade de trabalho, e assim também o poder de excluir ou incluir os papéis que poderiam compor a sua identidade, como o de trabalhadora e mãe.

Quanto à identificação de Nice com a MDA, poder-se-ia falar de uma "extrema identificação" com a organização, o que pode ser algo bom ou ruim. No caso de Nice, por um certo tempo a organização foi fonte de realização e identidade, apresentando aspectos positivos. Mas sua "extrema identificação" à organização apresentava também aspectos negativos, como a ausência de crítica, uma consequência ruim, também apontada por Marra et al. (2016), e a dificuldade em separar a própria vida e a identidade pessoal da organização, o que a jogou em um estado de tristeza e perda com a sua saída da MDA. Quando os ideais não podem mais ser atingidos, ou não se consegue mais acreditar neles, vem a frustração, a ilusão cede espaço à desilusão. Mas, no caso de Nice, veio o silêncio, nenhuma queixa foi feita, o que mais the doeu foi o seu bebê, a perda da possiblidade, ao menos por um tempo, de exercer o seu papel de mãe, também a frustração da demissão, e a perda das condições materiais de sustento. Em síntese, a história de Nice mostra sua trajetória desde a vida difícil na Universidade, tendo de conciliar a vida entre trabalho e estudo. Já neste percurso teve início o seu processo de idealização e identificação com a organização MDA, atenta a todos os processos seletivos conseguiu ingressar na organização, para a qual devotou a vida. Sua história revela assim um processo de identificação intenso com uma organização, sua fala revela que outros aspectos de sua vida ficaram em segundo plano, pois tudo o que fazia era se dedicar a esta organização; que, envolta em um caso de corrupção, fechou suas filiais no Brasil, demitindo milhares de trabalhadores, entre eles Nice, que teve de recomeçar a sua vida e até o término das entrevistas estava ainda procurando trabalho em outra organização. Algumas reflexões são possiveis e serão a seguir apresentadas.

\section{CONSIDERAÇÕES FINAIS}

O processo de corrupção que envolveu a organização em que Nice trabalhou e perpassou o seu drama explicita, conforme ressaltado por Colares e Saraiva (2016), a necessidade de reflexões em relação às práticas empregadas nas organizações que podem tornar os trabalhadores meros objetos em um teatro criado pelos gestores e pelo próprio capital.

Para Freitas (2006), submetendo-se à organização, o indivíduo trabalha com prazer, como se o fizesse para si próprio, pois ela faz parte dele. Nesse sentido, a organização oferece um sistema de crenças e valores, um ideal de vida, a possibilidade concreta de realizar alguns desejos, uma maneira de viver relativamente coerente, e tudo isso responde às necessidades profundas que todo ser humano traz em si. Eis por que os indivíduos aceitam as restrições e os preços que lhes são cobrados, em particular o estresse, a carga de trabalho e a intensidade do investimento pessoal e psíquico que eles fazem para garantir a satisfação de serem admirados, amados e reconhecidos. Eles são cúmplices, presos na armadilha que thes preparam seus próprios desejos, medos e fantasmas.

A história de Nice denota que as mudanças que ocorreram em MDA, geradas por um escândalo de corrupção, representaram um rompimento em sua história, sendo necessário um recomeço (BACKES, 2013), não sem prejuízos à sua identidade de trabalhadora e mãe. As condições objetivas (MININI; FERRAZ, 2015) que Nice experienciou no contexto organizacional de MDA futuramente podem fragilizar os processos identificatórios com outras organizações, como assinalado por Lorenz et al. (2014) e por Colares e Saraiva (2016), quando indicam a grande influência do contexto, dos agentes sociais e das instituições na formação da identidade de cada pessoa. A história de Nice e sua trajetória em MDA, transpassadas por um processo de corrupção, asseveram o quanto as organizações como espaços de lutas identitárias e jogos de poder (CABANA; ICHIKAWA, 2017) revelam 0 poder de definir a identidade, de incluir e excluir papéis. No caso de Nice em especial sua identidade de trabalhadora e mãe.

Assim, esta pesquisa contribui teoricamente para os estudos organizacionais ao destacar a influência das organizações no processo de constituição da identidade dos seus trabalhadores, destacando que esta construção identitária se dá por processos de identificação com as organizações, permeados por conflitos, jogos de poder, rupturas e, no caso de Nice, um escândalo de corrupção que perpassou o seu drama. Contribui também ao indicar que, por vezes, ocorre a necessidade de um recomeço em outras organizações ou contextos, não sem prejuízos à identidade do trabalhador, o que convida a uma reflexão crítica sobre estes acontecimentos e seus atores. 
Como sugestão para pesquisas futuras se propõe, por exemplo, o estudo: de como os processos de demissão impactam na construção identitária dos trabalhadores; quais as relações entre desidentificação e doenças ocupacionais; as relações entre a super identificação e a ansiedade; ou, ainda, investigar como as mudanças alteram a identificação dos trabalhadores em relação às suas organizações.

Enfim, que este artigo seja dedicado a todas as Nices que trabalham todos os dias em diferentes organizações, e que apesar de seus dramas pessoais, contribuem para o desenvolvimento das organizações e da nossa sociedade.

\section{REFERÊNCIAS}

ASHFORTH, B. E.; MAEL, F. A. Organizational identity and strategy as a context for the individual. Advances in Strategic Management, 1996.

ALPERSTEDT, G. D.; FERREIRA, J. B.; SERAFIM, M. C. Empreendedorismo feminino: dificuldades relatadas em histórias de vida. Revista de Ciências da Administração, v. 16, n. 40, p. 221-234, 2014.

AUBERT, N. A neurose profissional. In: CHANLAT, J. F. (Org.) 0 indivíduo na organização: dimensões esquecidas. São Paulo: Atlas, 1994. v.2.

ALBERT, S.; WHETTEN, D. A. Organizational identity. In: LARRY, L. C.; BARRY, M. S. (Eds.), Research in organizational behavior. An annual series of analytical essays and critical reviews, Greenwich: JAI Press. 1985. p. 263-295.

BACKES, A. L. Mudança Organizacional na Perspectiva Subjetiva do Funcionário: implicações na Sustentação e Reconstrução de Sua Identidade. GESTÃO.Org - Revista Eletrônica de Gestão Organizacional, v. 11, n. 3, p. 23-37, 2013.

BARDIN, L. Análise de conteúdo. Lisboa: Edições 70, 2012.

BERGER, P. L.; LUCKMAN. Papéis. In: BERGER, P. L.; LUCKMAN. A construção social da realidade: tratado de sociologia do conhecimento. Petrópolis: Vozes, 1973.

BERGER, P. L.; LUCKMAN. Papéis. In: BERGER, P. L.; LUCKMAN. A construção social da realidade: tratado de sociologia do conhecimento. Petrópolis: Vozes, 2012.

BONIFÁCIO, R; RIBEIRO, E. Corrupção e participação política no Brasil: diagnósticos e consequências. Revista Brasileira de Ciência Política, n.20, p.7-42, Brasília, 2016.

BREAKWELL, G. Métodos de entrevista. In: BREAKWELL, G.; HAMMOND, S.; FIFE-SCHAW, C; SMITH, J. A. Métodos de pesquisa em Psicologia. 3. ed. Porto Alegre: Bookman, 2010.

BROWN, A. D. Identities and identity work in organizations. International Journal of Management Reviews, $v$. 17, n. 1, p. 20-40, 2014.

CABANA, R. D. P. L.; ICHIKAWA, E. Y. As Identidades Fragmentadas no Cotidiano da Feira do Produtor de Maringá. Organizações \& Sociedade, v. 24, n. 81, p. 285-304, 2017.

CALDAS, M. P.; WOOD JR., T. Identidade organizacional. RAE - Revista de Administração de Empresas São Paulo, v. 37, n. 1, p. 6-17, 1997.

CARDOSO, M. A. F.; HANASHIRO, D. M. M.; BARROS, D. L. P. Um caminho metodológico pela análise semiótica de discurso para pesquisas em identidade organizacional. Cadernos EBAPE.BR, v. 14, n. 2, p. 351-376, 2016.

CARRIERI, A. P. (Org.) et al. Identidade nas organizações. Curitiba: Editora Juruá, 2010.

CARRIERI, A. P.; SANTOS, J. V. P. D.; PEREIRA, V. F.; MARTINS, T. S. Pesquisa Histórica em Administração:

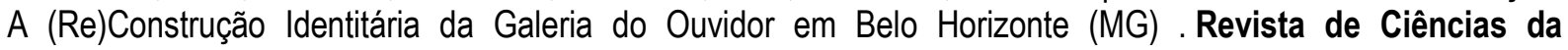
Administração, v. 18, n. 46, p. 9-22, 2016.

CASTELLS, M. 0 poder da identidade. Rio de Janeiro: Ed. Paz e Terra, 2013.

CHENEY, G.; CHRISTENSEN, L.T.; DAILEY, S. Communicating identity and identification in and around organizations. In: PUTNAM, L. L.; MUMBY, D. K. (Ed.). The SAGE Handbook of Organizational 
Communication: Advances in Theory, Research, and Methods. 3. ed., Chapter 28, Los Angeles: Sage Publications, Incorporated. 2014. p. 695-716.

COLARES, A. F. V.; SARAIVA, L. A. S. O Processo de Construção Identitária em Organizações: Uma Releitura Sobre Identidade. Revista Alcance, v. 23, n. 4, p. 568-577, 2016.

CORBETTA, P. Social research: theory, methods and techniques. London: Sage, 2003.

CORREA, M. V. P.; LOURENÇO, M. L. A constituição da identidade dos professores de pós-graduação stricto sensu em duas instituições de ensino superior: um estudo baseado nas relações de poder e papéis em organizações. Cadernos EBAPE.BR, v. 14, n. 4, p. 858-871, 2016.

CLOSS, L. Q.; OLIVEIRA, S. R. História de Vida e Trajetórias Profissionais: Estudo com Executivos Brasileiros. Revista de Administração Contemporânea, v. 19, n. 4, p. 525-543, 2015.

CRESWELL, J. W. Projeto de pesquisa: métodos qualitativo, quantitativo e misto. 3. ed. Porto Alegre: Bookman, 2010.

CRESWELL, J. W. Qualitative inquiry and research design: Choosing among five traditions. SAGE, 1998.

DENZIN, N.K.; LINCOLN, Y. S. e colaboradores. 0 planejamento da pesquisa qualitativa: teorias e abordagens. Porto Alegre: Bookman e Artmed, 2006.

DUKERICH, J.M.; KRAMER, R.; PARKS, J.M. The Darks Side of Organizational Identification. In: WHETTEN, D. A.; GODFREY, P. C. (Org.) Identity in organizations: Building Theory Trough Conversations. London: SAGE Publications, 1998. p.245-256.

DUTTON, J.E; DUKERICH, J. M.; HARQUAIL, C. V. Organizational Images and Member Identification. Administrative Science Quartely, v. 39, n. 2, 1994.

ENRIQUEZ, E. A organização em análise. Petrópolis, RJ: Vozes, 1997.

FERNANDES, M. E. R.; MARQUES, A. L.; CARRIERI, A. P. Elementos para compreensão dos estudos de identidade em teoria organizacional. In: CARRIERI, A. P. (Org.) et al. Identidade nas organizações. Curitiba: Editora Juruá, 2010.

FERREIRA, J. F.; GODOY, A. S. Processos de Aprendizagem: Um Estudo em Três Restaurantes de um Clube Étnico Alemão de Negócios, Gastronomia e Cultura. Revista de Administração Mackenzie, v. 16, n. 2, p. 15-44, 2015.

FREITAS, M. E A questão do imaginário e a fronteira entre cultura e organização e a psicanálise. In: MOTTA, P; FREITAS, M. E. DE. Vida psíquica e organização. 2. ed. Rio de Janeiro: FGV, 2002. p. 41-75.

FREITAS, M. E. Cultura Organizacional: Evolução e Crítica. Ed. Cencage Learning, 2007. p.01-10.

FREITAS, M. E. Cultura organizacional: identidade, sedução e carisma? Rio de Janeiro: Editora FGV, 2006.

GODOI, C. K; BALSINI, C. P. V. A pesquisa qualitativa nos estudos organizacionais brasileiros: uma análise bibliométrica. In: GODOI, C. K; BANDEIRA-DE-MELLO, R; SILVA, A. B. Pesquisa qualitativa em estudos organizacionais: paradigmas, estratégias e métodos. São Paulo: Saraiva, 2010.

HANELL, F. Teacher trainees performance of information sharing activities and identity positions on Facebook. Journal of Documentation, v. 73, n.2, 2017.

HATCH, M. J.; SCHULTZ, M. Organizational Identity. Oxford University Press. 2004.

LA BOÉTIE, E. Discurso sobre a servidão voluntária (1549). Editora Martin Claret, 2010.

LAPLANCHE, J.; PONTALIS, J. B. Vocabulário da Psicanálise. 8. ed. São Paulo: Martins Fortes Editora. 1985.

LORENTZ, C. N.; LIMA, L. C.; DIAS, B. O. S. V.; GUIMARÃES, L. V. M. Subjetividade e identidade dos gerentes frente aos novos papéis exigidos no atual contexto organizacional. Revista Gestão \& Tecnologia, v. 14, n. 3, p. 219-243, 2014.

LOURENÇO, M. L.; VOGT, S. CORREA, M. V. P. Identidade em organizações: produção científica no Brasil no período de 2004-2013. Revista Cesumar Ciências Humanas e Sociais Aplicadas, v.19, n.2, p. 463-486, jul./dez. 2014. 
MACHADO-DA-SILVA, C.L.; NOGUEIRA, E. E.S. Identidade Organizacional: um Caso de Manutenção, outro de Mudança. RAC, Edição Especial 2001.

MACHADO, H. V. A identidade e o Contexto Organizacional Perspectivas de Análise. Revista de Administração Contemporânea, Edição Especial, 2003.

MARRA, A. V.; FONSECA, J. A.; MARQUES, A. L. O processo de identificação organizacional frente à Reforma Administrativa: um estudo exploratório. Revista de Administração Mackenzie, v. 15, n. 1, p. 49-72, 2014.

MININI, R. M.; FERRAZ, D. L. S. A identidade de enfermeiros supervisores em um hospital público de Belo Horizonte. Gestão \& Conexões, v. 4, n. 1, p. 165-186, 2015.

MIRANDA, A. R. A.; CAPPELLE, M. C. A.; MAFRA, F. L. N. Contribuições do Método História de Vida para Estudos Sobre Identidade: o exemplo do estudo sobre professoras gerentes. Revista de Ciências da Administração, v. 16, n. 40, p. 59-74, 2014.

MOTTA, F. C. P. Organizações: vínculo e imagem. Revista de Administração de Empresas, v. 31, n.3, 1991, p. 5-11.

OLIVEIRA, E.J.; CORREA, D.A.; DELBONI, C. Meu nome é Ozires, Ozires Silva: a história de vida e de carreira de um empreendedor na perspectiva da teoria desenvolvimentista de Donald Super. In: EnGPR - ENCONTRO DE GESTÃO DE PESSOAS E RELAÇÕES DE TRABALHO. 6. Anais... Rio de Janeiro: ANPAD, 2017. p. 02-09.

OLIVEIRA, S.R.; CLOSS, L.Q. História de Vida e Trajetórias Profissionais: uma proposta interdisciplinar para os estudos de carreira. In: EnGPR - ENCONTRO DE GESTÃO DE PESSOAS E RELAÇÕES DE TRABALHO, 4. Anais... Rio de Janeiro: ANPAD, 2013. p.01-16.

PAGÈS, M. et al. 0 poder das organizações. São Paulo: Atlas, 1987.

RICHARDSON, R. J. Pesquisa social: métodos e técnicas. São Paulo: Atlas, 1989.

SCHIRATO, M. A. R. O Feitiço das Organizações: Sistemas Imaginários. São Paulo: Atlas. 2000.

STAKE, R. E. The art of case study research. Sage, 1995.

TONELLI, M. J.; CALDAS, M. P. Individualismo e desejo contraditório na formação de grupos. In: MOTTA, F. C. P.; FREITAS, M. E. DE. Vida Psíquica e Organização. 2. ed. Editora FGV. 2002.

VERGARA, S. C.; BRANCO, P. D. Empresa humanizada: a organização necessária e possível. RAE-publicações: Revista de Administração de Empresas, v. 41, n. 2, p. 20-30, 2001.

VIEIRA, A. Identidade e crise de identidade: reflexões conceituais. In: VIEIRA, A.; GOULART, I. B. (Orgs.). Identidade e subjetividade na gestão de pessoas. Curitiba: Juruá Editora, 2012.

SPINDOLA, T; SANTOS, R. Da S. Trabalhando com a história de vida: percalços de uma pesquisa(dora?). Revista Escola de Enfermagem - USP, v. 37, n.2, 2003.

NOGUEIRA, M. L. Mobilidade psicossocial: a história de Nil na cidade vivida. Dissertação (Mestrado) - FAFICH. Belo Horizonte: FAFICH, 2004.

SILVA, A. P. et al. "Conte-me sua história": reflexões sobre o método de História de Vida. Mosaico estudos em psicologia, v. 1, n.1, p. 25 -35, 2007.

WAIANDT, C.; JUNQUILHO, G. S. Representações familiares a partir da gestão: um estudo do caso de uma indústria de bebidas. Revista Interdisciplinar de Gestão Social, v. 1, n. 2, p. 141-161, 2012.

WARREN, M. The meaning of corruption in democracies. In: HEYWOOD, P. (Ed.). The Routledge international handbook on political corruption. Oxford: Routledge, 2012. 